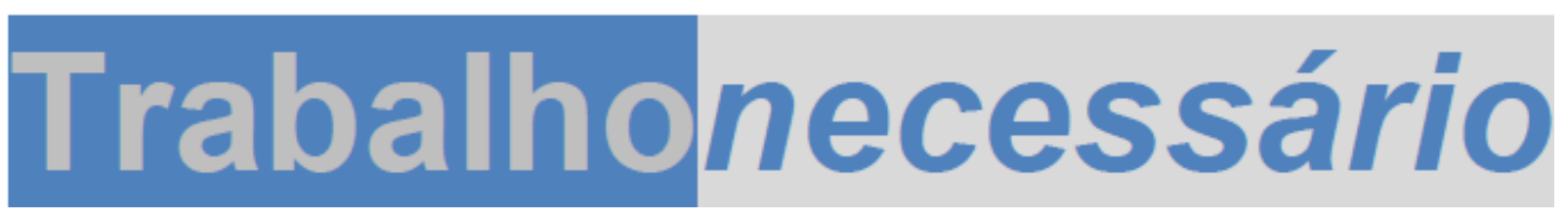

Issn: 1808 - 799X

ano 10, no $15-2012$

\title{
CURRÍCULO INTEGRADO NA EDUCAÇÃO DE JOVENS E ADULTOS: APONTAMENTOS A PARTIR DO MAPEAMENTO DE UMA REDE DE PESQUISAS ${ }^{1}$
}

\author{
Abelardo Bento Araújo ${ }^{2}$ \\ Maria Aparecida da Silva ${ }^{3}$
}

Resumo: Este artigo resulta de uma investigação da produção acadêmica sobre Educação Profissional integrada à Educação de Jovens e Adultos, na qual se analisam aspectos ligados ao currículo. Constituem objeto de análise dissertações de Mestrado e teses de Doutorado defendidas no âmbito de Instituições de Ensino Superior que integram um programa nacional de pesquisa. Utiliza-se da metodologia inerente ao estado da arte ou estado do conhecimento, de caráter inventariante e descritivo, adentrando a análise. Os resultados confirmam a centralidade do currículo na modalidade de educação e revelam questões que o atravessam. Questiona-se a sucessão de programas de Educação Profissional no País, que impede a formação de cultura escolar favorável à integração curricular.

Palavras-chave: Currículo Integrado na Educação de Jovens e Adultos. Produção Cientifica. Proeja.

Abstract: This article results from an investigation of academic production on Professional Education Integrated Education for Youngs and Adults, in which we analyze aspects related to the curriculum. They are the object of analysis Masters dissertations and Doctoral theses defended within Institutions of Higher Education that integrate a national research program. We use the methodology inherent in the state of the art or state of knowledge, character and descriptive executor, penetrating analysis. The results confirm the centrality of the curriculum in the form of education and reveal issues that cross. We discuss succession of Professional

\footnotetext{
1 Artigo oriundo de dissertação de mestrado defendida por Abelardo Bento Araújo, sob a orientação da Professora Maria Aparecida da Silva, junto ao Mestrado em Educação Tecnológica do Centro Federal de Educação Tecnológica de Minas Gerais (CEFET-MG).

${ }_{2}^{2}$ Mestre em Educação Tecnológica pelo Centro Federal de Educação Tecnológica de Minas Gerais (CEFET-MG). E-mail: belo20rpm@yahoo.com.br

${ }^{3}$ Doutora em Educação - Unicamp; professora do Centro Federal de Educação Tecnológica de Minas Gerais (CEFET-MG). E-mail: masilva988@hotmail.com
} 


\section{Trabalhonecessário}

Issn: 1808 - 799X

ano 10, no $15-2012$

Education programs in the country, which prevents the formation of school culture conducive to curriculum integration.

Keywords: Integrated Curriculum in the Education of Youngs and Adults. Scientific Production. Proeja. 


\section{Trabalhonecessário}

Issn: 1808 - 799X

ano 10, no $15-2012$

\section{Introdução}

Este artigo tem como objetivo apreender questões ligadas ao Currículo Integrado na Educação de Jovens e Adultos a partir de dissertações e teses no âmbito do Programa de Apoio ao Ensino e à Pesquisa Científica e Tecnológica em Educação Profissional Integrada à Educação de Jovens e Adultos (Proeja Capes/Setec), desenvolvido no período 2006-2011, no Brasil, visando à formação de pesquisadores e a produção de conhecimento sobre essa modalidade de ensino. Esse currículo se torna realidade a partir do Programa de Integração da Educação Profissional com a Educação Básica na Modalidade de Educação de Jovens e Adultos (Proeja), lançado no ano de 2005, pelo Ministério da Educação (MEC), via Decreto № 5.478, de 24 de junho de 2005, no âmbito da Rede Federal de Educação Profissional e Tecnológica. O Decreto №. 5.840, de 13 de julho de 2006, denomina-o Programa Nacional de Integração da Educação Profissional com a Educação Básica na Modalidade de Educação de Jovens e Adultos, permanecendo a sigla, e permitiu sua oferta por estados, municípios e Sistema $S^{4}$, também no nível Fundamental de ensino, além do Médio.

Algumas ações viabilizadoras foram propostas pela Secretaria de Educação Tecnológica (Setec) do MEC, entre elas: a) oferta de pós-graduação lato sensu e de cursos de extensão, para docentes e gestores; b) instituição de grupos de pesquisa, para consolidar epistemologicamente a área no País; c) vinculação desses projetos de pesquisa aos programas de pós-graduação stricto sensu para inclusão de linhas de pesquisa sobre Educação Profissional Integrada à Educação de Jovens e Adultos; d) assistência estudantil para a permanência ao aluno Proeja; e) projeto de inserção contributiva para superação da evasão; f)

\footnotetext{
${ }^{4}$ Composto por Senai - Serviço Nacional de Aprendizagem Industrial; Sesi - Serviço Social da Indústria; Senac - Serviço Nacional de Aprendizagem do Comércio, entre outras.
} 


\section{Trabalhonecessário}

Issn: 1808 - 799X

ano 10, no $15-2012$

apoio à realização de fóruns fomento à elaboração de material didáticopedagógico e teórico-metodológico (BRASIL, 2007).

Privilegiando as questões relacionadas ao currículo, neste artigo, destacam-se as ações viabilizadoras referentes à formação de mestres e doutores e à produção de conhecimento sobre o tema. Utiliza-se da metodologia das pesquisas de estado do conhecimento ${ }^{5}$, por tomar como objeto a produção teórica em um determinado campo. A coleta de dados ocorreu entre 3 de novembro de 2011 e 20 de junho de 2012. Das 61 dissertações e oito teses identificadas, oito dissertações e três teses não puderam ser acessadas, por não estarem disponíveis até a data de encerramento ${ }^{6}$.

\footnotetext{
5 "Os estudos realizados a partir de uma sistematização de dados, denominada 'estado da arte', recebem esta denominação quando abrangem toda uma área do conhecimento, nos diferentes aspectos que geraram produções." (ROMANOWSKI; ENS, 2006, p. 39 - grifo das autoras). Já "o estudo que aborda apenas um setor das publicações sobre o tema estudado vem sendo denominado de "estado do conhecimento" (ROMANOWSKI; ENS, 2006, p. 40 - grifo das autoras). ${ }^{6}$ As onze produções das quais não se acessaram os textos completos são:

\begin{tabular}{|c|c|c|c|}
\hline Autor & Título & Ano - T/D & Inst. \\
\hline ANDRADE, V. S. & $\begin{array}{l}\text { A sequência FEDATHI e o ambiente virtual de ensino: telemeios na } \\
\text { determinação da equação de uma reta }\end{array}$ & 2011-D & UFCE \\
\hline $\begin{array}{l}\text { BARBOSA FILHO, } \\
\text { C. J. }\end{array}$ & $\begin{array}{l}\text { Entre o campo e a cidade: a oferta de educação profissional do campo } \\
\text { no espaco/lugar de contato }\end{array}$ & $2011-D$ & UFES \\
\hline BATISTA, A. S. & $\begin{array}{l}\text { Políticas públicas de EJA no município de Serra: impossibilidades e } \\
\text { desafios do PROEJA-FIC }\end{array}$ & 2011- D & UFES \\
\hline BONFIM, C. L. & $\begin{array}{l}\text { Os desafios da formação continuada de docentes para atuação na } \\
\text { Educacão Profissional articulada à educacão de jovens e adultos }\end{array}$ & 2011- D & UnB \\
\hline ESLABÃO, L. C. & $\begin{array}{l}\text { PROEJA: um dispositivo da governamentalidade produzindo posições } \\
\text { de sujeito }\end{array}$ & $2011-\mathrm{T}$ & UFPel \\
\hline FONSECA & Ensino de Ciências da Natureza no Proeja & $2011-\mathrm{T}$ & UENF \\
\hline MACHADC & Uso de episódios da história da ciência em aulas d & 20 & UENF \\
\hline MARTIN & $\begin{array}{l}\text { Estudo dos modelos mentais elaborados por alunos do Proeja sobre } \\
\text { temas de Física Moderna: contribuições para o planejamento do ensino } \\
\text { e como ferramenta de meta-cogniçâo. }\end{array}$ & $2011-\mathrm{T}$ & UENF \\
\hline MOREIRA, C. C. S. & $\begin{array}{l}\text { A opção dos educandos pela formação na Educação de Jovens e } \\
\text { Adultos e na Educação Profissional Técnica de nível médio integrada ao }\end{array}$ & 2011-D & UnB \\
\hline OLIVEIR/ & $\begin{array}{l}\text { O Proeja como instrumento de inclusão social: o caso dos egressos do } \\
\text { IFMG - campus Bambuí }\end{array}$ & $2009-D$ & UFV \\
\hline OLIVEIRA, M. R. & História da ciência no ensino de termologia para o Proeja & 2011- D & UENF \\
\hline
\end{tabular}
}




\section{Trabalhonecessário}

Issn: 1808 - 799X

ano 10, no $15-2012$

A discussão sobre a (re)integração entre Educação Profissional (EP) e Educação Geral e sobre EP integrada à Educação de Jovens e Adultos (EJA) se pautou pelos referenciais da formação humana integral socialista, especialmente marxista/gramsciana. Quando se trata do Currículo Integrado na EJA, insere-se a dimensão da experiência que o adulto traz para o ambiente escolar, entendida como experiência de classe. Como o campo do Currículo não surgiu de necessidade intelectual de pesquisadores, mas de necessidades educacionais reais que reclamavam propostas (SACRISTÁN, 2000), os estudos sobre Currículo Integrado na EJA até agora apontam mais pontos de partida do que de chegada.

Neste artigo, além da Introdução, apresenta-se a rede de pesquisa como estratégia para produzir conhecimentos sobre EP integrada à EJA (segunda parte), a síntese a partir dos resultados das produções acadêmicas analisadas (terceira parte) e a análise externa a essas produções (quarta parte). Por fim, tecem-se as considerações finais.

\section{Pesquisa em rede como suporte ao Proeja: visão sinótica dos resultados}

A carência de pesquisas sobre a integração entre Educação Profissional e Educação de Jovens e Adultos foi justificativa para a Setec/MEC criar o Programa de Apoio ao Ensino e à Pesquisa Cientifica e Tecnológica em Educação Profissional Integrada à Educação de Jovens e Adultos (Proeja - Capes/Setec). Esse programa resultou de um convênio entre a Setec e a Coordenação de Aperfeiçoamento de Pessoal de Nível Superior (Capes), por meio do Edital Proeja - Capes/Setec no 03/2006, para fomentar pesquisas sobre EP integrada à EJA. Nesse programa, foram aprovados nove projetos de ensino e pesquisa, conforme se demonstra no Quadro 1:

TrabalhoNecessário - www.uff.br/trabalhonecessario; Ano 10, № 15/2012. 


\section{Trabalhonecessário}

Issn: 1808 - 799X

ano 10, no $15-2012$

\section{Projetos de pesquisa instituídos no âmbito do Proeja - Capes/Setec}

\begin{tabular}{l} 
Título \\
\hline Políticas Públicas de Formação de \\
Jovens e Adultos para o \\
Desenvolvimento Sustentável: A \\
experiência do SENAC-SP e do \\
CEFETPS no período de 1976 a 2006
\end{tabular}

Formação e Produção Científica e Tecnológica em Educação Profissional Integrada à Educação de Jovens e Adultos

Demandas e Potencialidades do Proeja no Estado do Paraná

Escola, trabalho e cidadania: um estudo longitudinal com jovens e egressos e não ingressantes de um programa de inclusão de jovens

Educando Jovens e Adultos para a Ciência com Tecnologias de informação e Comunicação

O Proeja indicando a reconfiguração do campo da Educação de Jovens e Adultos com qualificação profissional desafios e possibilidades

Educação Profissional no Ensino Médio: Desafios da Formação Continuada de Educadores de Jovens e Adultos no âmbito do Proeja no Espírito Santo

ProejaTEC - Projeto de cooperação acadêmica entre a UFC, CEFET-CE e CEFET-PA, para fomento de ações colaborativas no âmbito do ProejaCapes/Setec

Experiências de Educação Profissional e Tecnológica Integrada à Educação de Jovens e Adultos no Estado do Rio Grande do Sul

Coordenador
Helena
Gemignani
Peterosi

Maria
Aparecida da
Silva
Domingos
Leite Lima
Filho
José Albertino
Carvalho
Lordêlo

Linhares

João Ferreira de Oliveira Edna Castro
Oliveira

Hermínio Borges Neto

Naira Lisboa Franzoi

Instituição líder
Centro Estadual de
Educação
Tecnológica Paula
Souza (CEETPS)
Centro Federal de
Educação
Tecnológica de
Minas Gerais
(CEFET-MG)

Universidade Tecnológica Federal do Paraná (UTFPR)

Universidade Federal da Bahia (UFBA)

Universidade

Estadual do Norte Fluminense Darcy Ribeiro (UENF)

Universidade Federal de Goiás (UFGO)

Universidade Federal do Espírito Santo (UFES)

Universidade Federal Instituto Federal do Ceará (IFCE); do Ceará (UFCE) Instituto Federal do Pará (IFPA)

Universidade Federal de Pelotas (UFPel); Universidade do Vale do Rio dos Sinos (UNISINOS); Universidade Estadual do Rio Grande do Sul (UERGS); Instituto Federal Sul-Riograndense (IFSUL); Instituto Federal Farroupilha (IFFarroupilha); Colégio Industrial Santa Maria (CTISM)

Fonte: $\quad$ FÓRUNS EJA BRASIL. Disponível em: <http://forumeja.org.br/pf/node/3>. Acesso em: 31 jan. 2012.

$\mathrm{Na}$ pesquisa, priorizam-se sete desses projetos, por terem investigado aspectos ligados ao Currículo Integrado. Excluem-se as produções realizadas no âmbito dos projetos coordenados pelo Centro Estadual de Educação Tecnológica 


\section{Trabalhonecessário}

Issn: 1808 - 799X

ano 10, no $15-2012$

Paula Souza (CEETPS) e pela Universidade Federal da Bahia (UFBA). O primeiro focalizou a história da Educação Profissional e o segundo se ocupou do Programa Nacional de Inclusão de Jovens (Projovem).

As pesquisas no âmbito do Proeja - Capes/Setec são definidas como pesquisas em rede, organizadas em torno de temas de interesse em comum, em instituições diferentes. Por constituir-se em parceria entre instituições, possibilita a transferência de experiência em pesquisa. Os temas eleitos a partir do conjunto das dissertações e teses estão descritos na TABELA 1.

\section{TABELA 1}

Dissertações e teses por tema

\begin{tabular}{lccc}
\hline \multicolumn{1}{c|}{ Categoria } & Quantidade & $\%$ \\
\hline Currículo Integrado na EJA & 23 & 33,33 \\
Implementação do Proeja & 12 & 17,39 \\
Sujeitos da EJA/Proeja & 11 & 15,94 \\
Acesso, evasão e permanência no Proeja & 6 & 8,69 \\
Inovação Curricular & 6 & 8,69 \\
Formação de professores para a EJA/Proeja & 5 & 7,25 \\
Saberes do Trabalho e Conhecimentos escolares & 3 & 4,35 \\
Representações da/na EJA/Proeja & 3 & 4,35 \\
\hline \multicolumn{1}{c}{ Total } & $\mathbf{6 9}$ & $\mathbf{1 0 0}$ \\
\hline
\end{tabular}

Fonte: Banco de Teses da Capes e Biblioteca Digital Brasileira de Teses e Dissertações. Disponível em: <http://capesdw.capes.gov.br/capesdw/> e <http://bdtd.ibict.br/>. Acesso em: 20 jun. 2012.

\section{Currículo Integrado na Educação de Jovens e Adultos: síntese a partir do Proeja - Capes/Setec}

O tema Currículo Integrado na Educação de Jovens e Adultos ganhou destaque no âmbito do Proeja - Capes/Setec (TABELA 1). Isso permite associar 


\section{Trabalhonecessário}

Issn: 1808 - 799X

ano 10, no $15-2012$

a discussão à centralidade do currículo, destacada nas reformas de Educação Básica, inclusive como reconhecimento do Banco Mundial (LOPES, 2004).

As dissertações e teses defendidas no âmbito do Proeja - Capes/Setec ressaltam possibilidades e limites, de modo específico em relação à integração curricular. Os limites da integração entre EP e EJA foram destacados em dissertações como a de Colontônio (2010, p. 98), que afirma que, se por um lado, isso não garante atenção à particularidade da EJA, por outro, o foco demasiado "[...] sobre a perspectiva metodológica da EJA também refuta o debate sobre integração a partir do eixo trabalho, cultura, ciência e tecnologia" (grifo da autora).

Diante da compreensão de que o currículo sofre pressões de diversas instâncias, as dissertações e teses apontam para as diferenças entre o prescrito e o realizado. (COSTA, 2009; IVO, RODRIGUES, 2009; CRIZEL, 2011; JACINTO, 2011). Esses limites vão dos documentos oficiais (RODRIGUES, 2009) ao confronto com as opções das instituições (PEIXOTO, 2009). Outros limites apontados são aqueles que independem da vontade dos professores e restringiram, em algumas instituições, a integração, de modo que esta não passasse da "[...] matrícula única, pela qual o aluno faz o ensino médio e a formação profissional de forma simultânea" (LOPES, 2009, p. 169). Outros ainda se caracterizam pela falta de reconhecimento do Proeja dentro das instituições (ARAÚJO, 2010), desconhecimento sobre as formas de organização do Currículo Integrado na EJA e da necessidade de ressignificação dos conhecimentos (AMARAL, 2010; COSTA, 2010).

As produções revelam, também, limites infraestruturais na implementação desse currículo (BARBOSA, 2010; IVO, 2010). Como alerta Gramsci (2011, p. 36), a escola única requer, de fato, "[...] uma enorme ampliação da organização prática da escola, isto é, dos prédios, do material científico e do pessoal docente". 


\section{Trabalhonecessário}

Issn: 1808 - 799X

ano 10, no $15-2012$

\subsection{Adesão e resistência de docentes e gestores: representações do público-alvo do Proeja}

A adesão e a resistência docente quanto à modalidade de EP integrada à EJA expressam-se no currículo em ação. Conforme Sacristán (2000), é na ação que está a expressão última do valor do currículo.

As dissertações e teses destacam que as representações de professores sobre o aluno da Educação de Jovens e Adultos são motivo da resistência de alguns professores ao Proeja. Trata-se da ideia de um aluno com capacidade de aprendizagem limitada, que não acompanhará o ritmo dos alunos em regularidade idade/série. Muitos comparam esse público com um ideal de aluno, que talvez não exista nem nos cursos ditos regulares (BOAVENTURA, 2010; NASCIMENTO, 2009; SANTOS, 2011; COSTA, 2010; COSTA, 2009; CORSO, 2009).

Isso leva, em alguns casos, os pesquisadores a verificarem que, para alguns gestores, a "[...] formação para esse público poderia ser qualquer uma, pois, de qualquer modo, eles não iriam aprender [...]" (KLINSKI, 2009, p. 78). Os alunos da EJA sabem quais os efeitos da representação sobre eles. Segundo Klinski (2009), esses alunos, após entrarem no curso, não querem ser chamados de alunos do Proeja e querem usar uniforme do Instituto Federal, pois isso os identifica como alunos de uma instituição de prestígio, que Ihes confere status.

Diante dessas questões, é importante resgatar a dissertação Silva, C (2011, p. 162), quando afirma que "não se trata [...] de culpabilizar o professor por todos os insucessos que podem decorrer dos processos escolares, mas, sim, [de] colocá-los no lugar de destaque e reforçar a crença de que são peças-chave nas escolas, no processo de ensino-aprendizagem [...]".

\subsection{Acesso, permanência, evasão e perfil do aluno: questões curriculares}

TrabalhoNecessário - www.uff.br/trabalhonecessario; Ano 10, № 15/2012. 


\section{Trabalhonecessário}

Issn: 1808 - 799X

ano 10, no $15-2012$

Com relação ao acesso aos cursos do Proeja, constituem desafios a divulgação e a seleção dos alunos. Diversas dissertações, ainda que com focos diferentes, colocaram em pauta o desafio que representa a realização de um processo seletivo para o Proeja. Sorteio, teste, entrevista, entre outros, foram utilizados pelas instituições para compor as turmas do Proeja, mas nenhum deles, isolado ou associado a outro, constitui-se em solução simples para uma seleção justa. Com relação à realização de um processo seletivo para o Proeja, os testes são o principal alvo das críticas. Esses são vistos pelos pesquisadores do Proeja - Capes/Setec como um meio de incluir os menos excluídos. Por meio de testes, os estudantes selecionados, mesmo sendo jovens e adultos afastados da escola, tenderiam a ser os que tiveram acesso a escolas melhores, em melhores condições, e se afastaram da escola há menos tempo.

Quanto à evasão, as dissertações e teses do Proeja - Capes/Setec mostram que ela se generalizou pelos diversos lugares onde o Proeja foi implementado (DEBIÁSIO, 2010; CARDOSO, 2010; NORO, 2011; KLINSKI, 2009). A evasão na EP integrada à EJA pode ser considerada um fracasso escolar reiterado, tendo em vista que os evadidos são, geralmente, os que mais tiveram sua escolarização fragmentada. Dentro da escola, concorrem para altas taxas de evasão fatores como a forma de ministrar o ensino, a carga horária, entre outros. Fora da escola, as pesadas cargas horárias de trabalho, o cansaço, entre outros. Além disso, a evasão converge para outra questão importante no desenvolvimento do Currículo Integrado na EJA, materializando-se na dificuldade da formação de turmas (SANTOS, C. 2011). Algumas dissertações constataram a presença de alunos com Ensino Médio concluído estudando nas turmas do Proeja (NASCIMENTO, 2009; KLINSKI, 2009; BENTO, 2009; HOTZ, 2010; ZANETTI NETO, 2009; CARDOSO, 2010). Os dados de Klinski (2009) revelam que o fato 


\section{Trabalhonecessário}

Issn: 1808 - 799X

ano 10, no $15-2012$

de os alunos terem concluído o Ensino Médio não provoca alteração. Ao contrário, a maioria diz que os processos de escolarização anteriores não the garantiram aprendizagem (KLINSKI, 2009).

No entanto, a questão é mais complexa. Na medida em que se admitem alunos com Ensino Médio concluído e alunos com trajetórias fragmentadas de escolarização e que ainda não concluíram esse nível de ensino, cria-se um problema com relação ao desenvolvimento do Currículo Integrado na EJA, pois se coloca em um mesmo espaço grupos com desempenhos diferentes. Do ponto de vista da interação, isso seria positivo, no entanto, a dissertação de Bento (2009) aponta para a segmentação desses alunos, com uma divisão em três grupos: universitários, alunos com Ensino Médio concluído e alunos com apenas o Ensino Fundamental. Os alunos do Proeja com trajetórias fragmentadas de escolarização se sentem inferiores diante dos que cursam ensino superior, especialmente.

Por se tratar de um público com trajetórias escolares fragmentadas, os alunos do Proeja encontram dificuldades no desenvolvimento das atividades curriculares. Siqueira (2010) e Noro (2011) apontaram como fator negativo percebido pelos alunos - em relação à integração curricular o número de disciplinas. Segundo Noro (2011), há disciplinas com conteúdos próximos, que poderiam compor núcleos menos fragmentados. Assim, se a permanência dos alunos do Proeja é motivada pela perspectiva de (re)inserção no mercado de trabalho, contraditoriamente, as questões curriculares contribuem para a evasão.

É necessário ressaltar, também, com base nessas teses e dissertações, as questões ligadas ao perfil do aluno da EP integrada à EJA, pois isso responde uma pergunta básica para o currículo: quem é o aluno ao qual se destina? A EP integrada à EJA é destinada a jovens e adultos que não tiveram acesso à escola na idade dita regular ou que tiveram que abandoná-la sem concluir a escolarização. Embora não fosse o foco, emergem das produções, os motivos

TrabalhoNecessário - www.uff.br/trabalhonecessario; Ano 10, № 15/2012. 


\section{Trabalhonecessário}

Issn: 1808 - 799X

ano 10, no $15-2012$

pelos quais os alunos abandonaram a escola. Essas pesquisas confirmam o fato de os alunos terem que optar entre escola e trabalho como motivo principal do abandono (LAMPERT, 2011). As produções também apontam a juvenização do público da EJA e, vinculada a essa, a indisciplina (CARDOSO, 2010; RODRIGUES, 2010; SILVA, C. 2011; ALMEIDA, 2008; OLIVEIRA, M. C. 2011).

\subsection{Formação e contratação de professores no Proeja}

A partir das concepções dos professores sobre trabalho e integração curricular, as produções apontam carência na formação docente. As concepções, segundo Corso (2009, p. 119), "[...] apontam para um esvaziamento do sentido do trabalho e do significado do trabalho como princípio educativo e ainda, em geral, a ausência de compreensão da proposta do Proeja". Quanto à relação Trabalho e Educação, em muitos casos, limita-se à referência, em sala de aula, ao que os alunos fazem ou farão (ALMEIDA, 2009). O trabalho é visto como necessidade de sobrevivência e autonomia financeira (ALMEIDA, 2009). Quando não evitam falar sobre a integração curricular (CORSO, 2009), as opiniões variam de atendimento à legislação a solução para a desmotivação discente (CAMPOS, 2010).

Ao compreender a formação docente no centro do debate do Currículo Integrado na EJA, as dissertações e teses analisadas não a tomam como mera preparação para a execução do currículo. Quanto a esse tema, as dissertações e teses destacam desde o fato de que as iniciativas governamentais atingem muito pouco os campi localizados no interior (NASCIMENTO, 2009), até a insuficiência da formação continuada ofertada pelo Estado no sentido de capacitar os professores para lidarem com as especificidades do público da EP integrada à EJA (SANTOS, R. 2011; CARVALHO, 2010). No entanto, algumas das produções analisadas constatam mudanças nas práticas dos professores, sinalizando para a

TrabalhoNecessário - www.uff.br/trabalhonecessario; Ano 10, №15/2012. 


\section{Trabalhonecessário}

Issn: 1808 - 799X

ano $10, \mathrm{n}^{\mathrm{0}} 15-2012$

efetivação da integração no currículo em ação (LIRA, 2011). Algumas dissertações e teses mostraram, por exemplo, que a integração entre a área profissional e a área propedêutica ficou comprometida por falta de professores da primeira. A carência obrigou os gestores e professores a planejarem as disciplinas dessa área para a parte final do curso, na esperança de posteriores contratações. Esse ajuste foi feito tendo em vista o cumprimento de prazos para implantar o Proeja (CAMPOS, 2010; BARBOSA, 2010; SIQUEIRA, 2010; HOTZ, 2010).

\subsection{Planejamento dos cursos do Proeja}

Tensões também são reveladas no que se refere ao planejamento do Currículo Integrado na EJA. Algumas produções chegam a se configurar como denúncias, como a dissertação de Garcia (2011). Segundo o autor, a empresa contratada para assessorar a implementação do Proeja no estado de Goiás elaborou as propostas, sem a participação dos professores e gestores. Assim, esses projetos apenas "[...] cumprem uma necessidade burocrática e deixam de ser alvo de preocupação dos professores, que passam a ter essa exigência político-pedagógica cumprida por um serviço contratado [...]" (GARCIA, 2011, p. 83). Para Cardoso (2010), essa empresa deturpou a formação dos profissionais e a proposta do Proeja, pois, "[...] ao direcionar a elaboração dos planos de cursos voltada para as expectativas do mercado, não contemplou a formação integral do aluno proposta pelo programa" (CARDOSO, 2010, p. 123).

Hotz (2010) também constata nos planos de curso do Proeja na rede estadual do Paraná a deturpação da proposta da integração curricular. Já Campos (2010) verifica que, na implementação do Proeja em Rio Verde-GO, em 2006, o plano de Curso foi elaborado com a parceria entre as Instituições da Rede Federal em Goiás e a Secretaria de Estado da Educação de Goiás. "Essa 


\section{Trabalhonecessário}

Issn: 1808 - 799X

ano 10, no $15-2012$

parceria, contudo, não foi firmada somente para a execução do programa; ela existia com a cessão de professores concursados ou contratados pela Secretaria de Educação para ministrar disciplinas nos diversos cursos técnicos" (CAMPOS, 2010 , p. 95). A autora verifica, nas falas dos gestores, que os planos de cursos foram copiados dos já ofertados na instituição na modalidade regular de EP. Mais apontamentos do planejamento como cumprimento da burocracia estão nas considerações de Silva (2010), Hotz (2010), Gotardo (2009) e Nascimento (2009).

Por fim, é importante destacar o alerta feito por Silva (2010), em sua dissertação, com relação à formação dos professores do Proeja no estado do Paraná. Segundo a autora, a capacitação realizada não agradou aos professores, porque muitos deles se sentiam na "periferia" da discussão. Em outras palavras, a formação inicial desses professores não lhes permitiu discutir questões básicas como as colocadas pelas teorias do currículo, como iniciar a discussão a partir do Currículo Integrado?

\subsection{Material didático e Currículo Integrado na Educação de Jovens e Adultos}

Vale lembrar que há fatores que pressionam o currículo, tais como os materiais didáticos. Além de servir ao controle das atividades, esses materiais contribuem para a desprofissionalização do professor, à medida que usurpam a função docente na seleção, elaboração e sequenciação de conteúdos e atividades (SACRISTÁN, 2000). Nas dissertações e teses do Proeja Capes/Setec, o material didático aparece como entrave à implementação do Currículo Integrado na EJA. Em determinadas circunstâncias, a elaboração de material didático específico ocorria com o pretexto da adaptação, mas, de fato, efetuavam-se resumos do conteúdo, partindo da suposição de que o aluno da EJA teria menores condições de aprendizado que os dos cursos regulares. 


\section{Trabalhonecessário}

Issn: 1808 - 799X

ano 10, no $15-2012$

(HOTZ, 2010; SANTOS; 2011; LOPES, 2011; BARBOSA, 2010; NASCIMENTO, 2009; COSTA, 2010; REPOLÊS, 2011; FREITAS, 2010). Salienta-se que somente em uma das produções analisadas, uma tese de doutorado sobre Educação Matemática (FREITAS, 2010), faz-se a análise de um processo de produção de material didático. Freitas (2010) constata resultados de mudança na aprendizagem dos alunos e receptividade do material, mas ressalta os limites desse tipo de produção por disciplina.

\subsection{Saberes do trabalho e conhecimentos escolares: possibilidades de integração epistemológica}

O aluno jovem e adulto trabalhador possui experiência, especialmente do mundo do trabalho, podendo trazê-la para a escola. Vale ressaltar, com base em Thompson (2002), que a experiência é uma categoria histórica e, por isso, deve ser compreendida de forma contextualizada, como experiência de classe.

Em sua dissertação, Barros (2010) aponta a necessidade de ultrapassar a afirmação de que todos possuem saberes extraescolares e da necessidade de considerá-los na escola. Para a autora, é preciso conhecer mais de perto que saberes são esses. A volta à escola, como "busca de conhecimento", caracterizase, para o aluno da EJA, em geral, como um "epistemicídio" (SANTOS, 2007, p. 29 apud BARROS, 2010, p. 127). Isso significa a morte dos conhecimentos alternativos, oriundos da experiência, em nome do conhecimento científico. É importante ainda considerar a ligação de alguns saberes à construção social do gênero. Os trabalhos como limpeza, cuidado, ainda são vistos por muitos alunos como saberes e habilidades femininas (CANTO, 2009).

Segundo Barros (2010), apesar do esforço dos professores em sala, não é desenvolvido planejadamente um ensino fundado na experiência do trabalho 


\section{Trabalhonecessário}

Issn: 1808 - 799X

ano 10, no $15-2012$

dos alunos. Essa relação é mais explorada na parte do currículo denominada técnica, no entanto, restrita ao utilitarismo do conhecimento. Oliveira, M. C. (2011) identifica a realização de projetos de pesquisa por alunos como possibilidade de aproximação dos saberes do trabalho e dos conhecimentos escolares. Nesse projeto, os alunos não lidam apenas com conhecimentos específicos para processarem os produtos da batata-doce, proposta central, mas com conhecimentos sociais, econômicos, políticos (OLIVEIRA, M. C. 2011). Noro (2011) também evidencia a criação de uma miniempresa, na qual os alunos tiveram a oportunidade de trabalhar com os conteúdos da área administrativa. Freitas (2010), ao tratar da necessária relação entre a Matemática cotidiana e a acadêmica, aponta como dificuldade dessa integração o fato de o conhecimento tácito não ser expresso em palavras e conceitos, mas estar ligado às ações.

Por fim, as produções analisadas apontam para as inovações curriculares, surgidas, sobretudo, a partir da pesquisa-ação. As dissertações que empregaram esta metodologia evidenciaram a possibilidade de inserção de novos temas no Currículo Integrado na EJA, como a velhice (GOMES, 2007), bem como a ampliação de conteúdos não valorizados no currículo da EJA, como a Arte (ZIM, 2010; RODRIGUES, 2010). Além disso, indicaram possibilidades de ensino por meio de plataformas virtuais, como apoio e alternativa ao desenvolvimento do currículo da EJA, para o aluno trabalhador (BASTOS FILHO, 2010), que não está incluído digitalmente (NUNES, 2011).

\section{Avanços, percalços e desafios na discussão do Currículo Integrado na Educação de Jovens e Adultos}

Nesta seção, faz-se uma análise externa às produções, discutindo-se tanto os resultados das pesquisas como suas características. Constata-se que as

TrabalhoNecessário - www.uff.br/trabalhonecessario; Ano 10, № 15/2012. 


\section{Trabalhonecessário}

Issn: 1808 - 799X

ano 10, no $15-2012$

dissertações e teses sobre o Proeja convergem em apontar a necessidade de o programa se tornar uma política pública. Destacam a intencionalidade manifesta no Documento Base de o programa tornar-se uma política de Estado (KLINSKI, 2010; GOMES, 2007, COSTA, 2010; RODRIGUES, 2009; BOAVENTURA, 2009; LOPES, 2009; AMARAL, 2010; ROCHA, 2011; CAMPOS, 2010) e questionam os limites dessa intencionalidade.

Os debates, apesar de convergirem no sentido dessa necessidade, não são unívocos. Por vezes, complementam-se, pois em uns constata-se a afirmação dessa necessidade, em outros parece haver adesão ao discurso. Diante da histórica fragmentação das políticas de EJA e das de EP, essas produções constatam a necessidade de continuidade. No entanto, as que analisam mais amplamente a questão concluem sobre uma contradição - afirmar uma política permanente para a EJA é afirmar também a contínua produção de sujeitos para a EJA. Diante dessa contradição, as produções não rechaçam o Proeja, mas verificam que, ao mesmo tempo em que se faz necessário reivindicar uma política de EJA, não se pode esquecer a crítica ligada à expansão quantitativa e qualitativa da Educação Básica no País.

Não obstante essas discussões, as relações entre o Proeja e o Estado ainda apresentam lacunas no âmbito da produção acadêmica. Importa ressaltar, nesse sentido, que a ideia de elevação da escolaridade integrada à formação profissional era praticada no âmbito sindical, antes de ser adotada no âmbito do Proeja. Vale lembrar que Poulantzas (1980) considera que o Estado não se define quanto à sua disposição nas mãos de uma classe (POULANTZAS, 1980). Assim, as políticas não o desobrigam da mediação das lutas sociais. Por conseguinte, questionam-se as possíveis diferenças entre o desenvolvimento desse tipo de educação pelo Estado e pelos sindicatos.

TrabalhoNecessário - www.uff.br/trabalhonecessario; Ano 10, № 15/2012. 


\section{Trabalhonecessário}

Issn: 1808 - 799X

ano 10, no $15-2012$

Quanto aos referenciais teóricos, com exceção de duas dissertações que utilizaram o referencial pós-moderno de Stephen Ball ${ }^{7}$ (IVO, 2010; COSTA, 2009) e os referenciais auxiliares na discussão de outros temas, a integração curricular foi analisada no âmbito do Proeja - Capes/Setec sob a perspectiva da formação humana integral de Gramsci. Foram também utilizados autores brasileiros na vertente desse filósofo, ainda que em associação com outros referenciais.

Os escritos de Gramsci relativos à educação caracterizam-se mais como oposição às propostas de reformas do ensino italiano. Porém, os debates que empreendeu em torno dessas questões possibilitaram-Ihe a explicitação de contrapropostas. O interesse de Gramsci pelas questões culturais diz respeito ainda à preocupação com a formação dos quadros dirigentes do futuro Estado Proletário. A questão já vinha sendo discutida no interior do Partido Socialista Italiano, com divergências entre Bordiga e Tasca - o primeiro não se preocupava com formação cultural do proletariado, já o segundo defendia, inclusive, que a revista $A$ vanguarda se tornasse órgão de cultura socialista (NOSELLA, 2010). Entre as defesas polarizadas de formação cultural e formação para o trabalho, Gramsci decide-se pela formação cultural do operariado, mas não sem tecer suas críticas a ambas as posições. O conceito de cultura, para Gramsci, é histórico, não enciclopédico (BUCl-GLUCKSMANN, 1980).

\footnotetext{
${ }^{7}$ Essa perspectiva surge em investigações que comparam a política e a prática do Proeja. $\mathrm{O}$ conceito de Performatividade serve à investigação dos processos de gestão aos quais são submetidas as escolas e sistemas educativos, investigando a ingerência do Estado por meio da transformação da cultura escolar. O Policy Cicle (Ciclo de Políticas) considera a dinâmica que ocorre entre a elaboração e a implementação de uma política, tornando-se alternativa para a compreensão das diferentes reconfigurações que se fazem em uma política, desde sua elaboração até a prática. Esse tipo de análise de política pública compreende que a participação dos sujeitos no processo implementação (como exercício de levara à prática) tenha uma dimensão reconfiguradora.
} 


\title{
Trabalhonecessário
}

Issn: 1808 - 799X

ano 10, no $15-2012$

\begin{abstract}
Do ponto de vista teórico-cultural, a primeira grande questão era integrar teórica e praticamente o mundo do trabalho com o mundo da cultura; a ciência produtiva com a ciência humanista; a escola profissionalizante com a escola desinteressada. Essa questão devia ser resolvida radicalmente e, para que isso ocorresse, o ponto de partida devia ser unitário. Gramsci havia aprendido, no estudo dos filósofos da imanência (idealista), que, se o ponto de partida da epistemologia não fosse integrado, jamais aquela filosofia se livraria do bipolarismo ou da dicotomia. Este unitário ponto de partida obviamente era, na concepção gramsciana, o trabalho industrial moderno, a fábrica. $\mathrm{Na}$ intimidade dessa "molécula" social moderna, via ele em filigrana o embrião germinativo de todas as novas formas de humanismo e de cultura: a comissão interna, o conselho de fábrica, o Sindicato, o Partido, a Economia Geral, enfim, a história e o socialismo; e, naturalmente, também a escola unitária. Essa concepção epistemológica constituía para Gramsci a sólida base teórica para pensar coerentemente uma sociedade, uma cultura e uma escola realmente unitárias e modernas (NOSELLA, 2010, p. 64, grifo nosso).
\end{abstract}

A simples articulação ou combinação de tempos escolares de ensino humanista e profissionalizante não era suficiente. Gramsci pretendeu integrar epistemologicamente o mundo do trabalho e o da cultura. "Não há atividade humana da qual se possa excluir toda intervenção intelectual, não se pode separar o homo faber do homo sapiens" (GRAMSCI, 2011, p. 52-53). Considerava necessário que, além de especialista, o homem também fosse político.

O Currículo Integrado, levando em conta os aspectos da EJA, representa uma impossibilidade numa sociedade capitalista, em que a formação tende a se orientar pela ocupação de postos de trabalho no setor produtivo. Todavia, o que se verificou no Proeja foi uma opção por fazer a reforma de cima para baixo. Do ponto de vista de concepção e fundamentação, o Proeja é coerente. No entanto, não se consultaram os sujeitos da prática - alunos e professores - antes de implantar o programa. É válido dizer que "[...] a teoria não faz o sistema: ela é apenas uma condição necessária para que ele se faça. Quem faz o sistema são os homens quando assumem a teoria na sua práxis. (SAVIANI, 2000, p. 119-120). Contudo, há que se destacar os limites do poder do professor de integrar em sala de aula algo que está dividido na própria sociedade (SILVA, M. R., 2011). 


\section{Trabalhonecessário}

Issn: 1808 - 799X

ano $10, \mathrm{n}^{\mathrm{0}} 15-2012$

Vale destacar que, pela análise das dissertações e teses, pode-se verificar que estas se pautaram no mesmo e único referencial teórico, o qual foi o que fundamentou a proposta do Proeja. No entanto, as análises efetuadas pelos autores dessas produções ficou carente de distanciamento teórico-metodológico para criticar tanto a proposta Proeja quanto sua implementação, a partir de categorias do método dialético que, subliminarmente, pareciam estar usando. Por decorrência, a maioria dos autores se limitou a concordar com a proposta, diminuindo os embates, próprios da dialética.

Pistrak (2000), ao tratar da necessidade da (re) educação do professor para um projeto de educação socialista, assegura que o objetivo dessa (re) educação não era "[...] fornecer-Ihe um conjunto de indicações práticas, mas armá-lo de modo que ele próprio seja capaz de criar um bom método, baseandose numa teoria sólida de pedagogia social; o objetivo é empurrá-lo no caminho desta criação" (PISTRAK, 2000, p. 25). O autor ressalta, ainda, que "[...] a teoria pedagógica comunista só se tornará ativa e eficaz quando o próprio professor assumir os valores de um militante social e ativo" (PISTRAK, 2000, p. 26).

As produções analisadas apontam, em diversos contextos em que foi implementado o Proeja, concepções distorcidas de professores acerca do que seja o trabalho como princípio educativo e a própria integração curricular. A questão converge para a necessidade da formação docente. Todavia, quando se atribui a viabilidade do Proeja ao domínio de conhecimentos pelos professores, caracteriza-se uma priorização das transformações de nível micro em detrimento das de nível macro na consecução dos objetivos desse projeto. Dessa forma, retoma-se uma ideologia positivista-eficientista, na qual os aspectos sociais e políticos que envolvem a educação tendem a ser desprezados. 


\section{Trabalhonecessário}

Issn: 1808 - 799X

ano 10, no $15-2012$

\section{Considerações finais}

O Currículo Integrado na EJA desafiou os campos, no sentido bourdieuano do termo, da EJA, do Currículo e de Trabalho e Educação, de onde vieram as bases teóricas para a discussão da integração entre EP e EJA. Dessa forma, o texto destacou algumas questões que atravessam esse currículo. A partir dessas questões, é possível colocar, também, alguns questionamentos. $O$ primeiro diz respeito à cultura escolar. Como o currículo se traduz por meio das práticas escolares, forma-se aí uma cultura. Apesar do impacto da entrada do aluno da EJA nas instituições, o caráter temporário do Proeja não permitiu que se consolidasse uma nova cultura, o que torna vulnerável a efetividade do programa.

Por fim, mas não menos importante, vale registrar que no momento em que a pesquisa em Currículo Integrado na EJA, no âmbito do Proeja Capes/Setec, poderia subsidiar algum tipo de mudança, o Programa é interrompido, sem nenhuma justificativa aos sujeitos da prática que 0 implementaram. Ao mesmo tempo, é instituído um novo programa de governo Programa Nacional de Acesso ao Ensino Técnico e Emprego (Pronatec), cujas bases teórico-metodológicas são antagônicas ao Proeja. Estaria de fato o Estado brasileiro, por intermédio da Setec/MEC, preocupado com a formação humana integral? Por que o Proeja que focalizava dimensões da integração formal, operacional e epistemológica é abandonado e em seu lugar se institui o Pronatec, que com ele se antagoniza? Por que desperdiçar a produção de pesquisa sobre o Proeja, se o objetivo do Proeja - Capes/Setec era consolidar uma área de pesquisa, para compreender problemas da prática e alcançar finalidades? As indagações podem ser, ao mesmo tempo, ponto de chegada e de partida. 


\title{
Trabalhonecessário
}

Issn: 1808 - 799X

ano 10, no $15-2012$

\section{REFERÊNCIAS}

AGUIAR, Gina Maria Porto de. PROEJA: análise acerca das potencialidades de inclusão sociolaboral dos alunos. 170 f. 2012. Dissertação (Mestrado em Educação). Universidade Federal do Ceará. Fortaleza-CE, 2011. Disponível em: $<$ http://www.teses.ufc.br/tde_busca/arquivo.php?codArquivo=6475>. Acesso em: 20 jun. 2012.

\begin{abstract}
ALMEIDA, Adriana de. Um estudo do e no processo de implantação no estado do Paraná do Proeja: problematizando as causas da evasão. $116 \mathrm{f}$. 2008. Dissertação (Mestrado em Educação). Universidade Federal do Paraná. Curitiba, 2008. Disponível em:

$<$ http://www.ppge.ufpr.br/teses/M08_adrianaalmeida.pdf>. Acesso em: 18 nov. 2011.
\end{abstract}

ALMEIDA, Luciana Maria de. Nas trilhas do fazer e do saber a possibilidade de ser: os caminhos do trabalho e da educação na prisão. 162 f. 2009.

Dissertação 9mestrado em Educação). Universidade Federal de Goiás. Goiânia, 2009. Disponível em:

$<$ http://forumeja.org.br/go/sites/forumeja.org.br.go/files/dissertacaoluciana.pdf>. Acesso em: 25 fev. 2012.

AMARAL, Antonio Elcio Padilha do. Ressignificando o conteúdo de segurança e saúde do trabalhador na formação de jovens e adultos do Instituto Federal do Pará - IFPA. 131 f. 2010. Dissertação (Mestrado em Educação). Universidade Federal do Ceará. Fortaleza - CE, 2010.

ARAÚJO, Ana Cláudia Uchoa. Avaliação do currículo integrado no Proeja do IFCE: concepção e prática na percepção do docente. 2010. 127 f. Dissertação (Mestrado em Educação). Universidade Federal do Ceará. Fortaleza, 2010.

BARBOSA, Roscelino Quintão. Uma análise sobre a implantação do Proeja: um estudo de caso no IFET sudeste de Minas Gerais - campus Rio Pomba (20062008). 146 f. 2010. Dissertação (Mestrado em Educação). Universidade de Brasília. Brasília-DF, 2010. Disponível em: $<$ http://repositorio.bce.unb.br/bitstream/10482/9119/1/2010_RoscelinoQBarbosa.p df>. Acesso em: 17 nov. 2011.

BARROS, Anália Bescia Martins de. A relação entre os saberes-experiência do trabalho e os saberes escolares, vista por alunos do Proeja do IFSUL de 


\section{Trabalhonecessário}

Issn: 1808 - 799X

ano 10, no $15-2012$

Sapucaia do Sul. 245 f. 2010. Dissertação (Mestrado em Educação). Universidade Federal do Rio Grande do Sul. Porto Alegre, 2010. Disponível em: $<$ http://www.lume.ufrgs.br/bitstream/handle/10183/24152/000744767.pdf?sequenc $\mathrm{e}=1$ >. Acesso em: 20 nov. 2011.

BASTOS FILHO, Ronaldo de Paula. Contribuição de um fórum virtual ao ensino de Física no Proeja. 106 f. 2009. Dissertação (Mestrado em Ciências Naturais). Universidade Estadual do Norte Fluminense. Campos do GoytacazesRJ, 2009. Disponível em:

<http://www.dominiopublico.gov.br/pesquisa/DetalheObraForm.do?select_action= \&co_obra=153408>. Acesso em: 10 mar. 2012.

BENTO, Jamilda Alves. O IFES e a implementação de políticas de inclusão social: o caso da educação de jovens e adultos. 138 f. 2009. (Mestrado em Educação). Universidade Federal do Espírito Santo. Vitória, 2009. Disponível em: <http://www.ppge.ufes.br/dissertacoes/2009/JAMILDA.pdf>. Acesso em: 18 nov. 2011.

BLUM, Márcia Sabina Rosa. A política de avaliação do Proeja no Estado do Paraná (2008-2010). 255 f. 2011. Dissertação (Mestrado em Educação). Universidade Estadual do Oeste do Paraná. Cascavel - PR, 2011. Disponível em: $<$ http://cac-

php.unioeste.br/pos/media/File/educacao/Dissertacao\%20Marcia\%20Blum.pdf>. Acesso em: 19 nov. 2011.

BOAVENTURA, Geisa D'avilla Ribeiro. O significado do Proeja no olhar e na voz de professores e alunos do Instituto Federal Goiano - campus Ceres. 139 f. 2010. Dissertação (Mestrado em Educação). Universidade de Brasília. Brasília-DF, 2010. Disponível em:

$<$ http://bdtd.bce.unb.br/tedesimplificado/tde_busca/arquivo.php?codArquivo=6583 >. Acesso em: 19 nov. 2011.

BRASIL. Decreto no. 5.478, de 24 de junho de 2005. Institui, no âmbito das instituições federais de educação tecnológica, o Programa de Integração da Educação Profissional ao Ensino Médio na Modalidade de Educação de Jovens e Adultos - Proeja. Brasília: Diário Oficial, 27 jun. 2005. Disponível em: <http://www.planalto.gov.br/ccivil_03/_ato2004-2006/2005/Decreto/D5478.htm>. Acesso em: 10 out. 2011. 


\section{Trabalhonecessário}

Issn: 1808 - 799X

ano 10, no $15-2012$

BRASIL. Decreto no. 5.840, de 13 de julho de 2006. Institui, no âmbito federal, o Programa Nacional de Integração da Educação Profissional com a Educação Básica na Modalidade de Educação de Jovens e Adultos - Proeja, e dá outras providências. Brasília: Diário Oficial, 14 jul. 2006. Disponível em: <http://www.planalto.gov.br/ccivil_03/_Ato2004-2006/2006/Decreto/D5840.htm>. Acesso em: 10 out. 2011.

BRASIL. Ministério da Educação. Programa Nacional de Integração da Educação Profissional à Educação de Jovens e Adultos (Proeja): formação inicial e continuada. Brasília: MEC/Setec, 2007. 79 p. Disponível em: $<$ http://portal.mec.gov.br/setec/arquivos/pdf2/proeja_fundamental_ok.pdf >. Acesso em: 10 out. 2011.

BRASIL. Ministério da Educação. Edital 003. Instruções para Apresentação de Projetos do Programa de Apoio ao Ensino e à Pesquisa Científica e Tecnológica em Educação Profissional Integrada à Educação de Jovens e Adultos - ProejaCapes/Setec. Brasília: Capes, 2006. Disponível em:

$<$ http://portal.mec.gov.br/index.php?ltemid=569\&id=12294\&option=com_content\& view=article $>$. Acesso em: 10 out. 2011.

BUCI-GLUCKSMANN, Christinne. Gramsci e o Estado: por uma teoria materialista da filosofia. Tradução: Angelina Peralva. 2. ed. Rio de Janeiro: Paz e Terra, 1980. 499 p.

CAMPOS, Camila Aparecida de. Os desafios da implementação do currículo integrado no Proeja em Rio Verde - GO. 141 f. 2010. Dissertação (Mestrado em Educação). Universidade Federal de Goiás. Goiânia, 2010. Disponível em: <http://forumeja.org.br/pf/sites/forumeja.org.br.pf/files/Camila\%20Campos\%20com pleta1.pdf>. Acesso em: 18 nov. 2011.

CANTO, Liana Pereira Machado. Narrativas de trabalhadoras domésticas estudantes da EJA e suas relações com o saber. 125 f. 2009. Dissertação (Mestrado em Educação). Universidade do Vale do Rio dos Sinos. São LeopoldoRS, 2009. Disponível em: <http://bdtd.unisinos.br/tde_arquivos/10/TDE-2009-0723T095646Z-797/Publico/CantoLianaPereiraMachadoEducacao.pdf>. Acesso em: 20 nov. 2011.

CANTU, Margarete. Qualificação profissional, inserção, reinserção e permanência no mercado de trabalho: os egressos do programa Integrar. $155 \mathrm{f}$. 2003. Dissertação (Mestrado em Sociologia). Universidade Federal do rio Grande 


\section{Trabalhonecessário}

Issn: 1808 - 799X

ano 10, no $15-2012$

do Sul - UFRGS. Porto Alegre, 2003. Disponível em:

$<$ http://www.lume.ufrgs.br/bitstream/handle/10183/2057/000363361.pdf?sequence $=1>$. Aceso em 25 fev. 2012.

CARDOSO, Edna Maria de Jesus. Impasses na implantação do Proeja no CEJA e no CEPSS na rede estadual de ensino de Goiânia: a distância entre o dito e o instituído. 156 f. 2010. Dissertação (Mestrado em Educação). Pontifícia Universidade Católica de Goiás. Goiânia, 2010. Disponível em: <http://tede.biblioteca.ucg.br/tde_busca/arquivo.php?codArquivo=895>. Acesso em: 21 fev. 2012.

CARVALHO, Jose Raimundo. História de vida de professores de língua portuguesa do Proeja no IFPA. 153 f. 2010. Dissertação (Mestrado em Educação). Universidade Federal do Ceará. Fortaleza - CE, 2010

CASTRO, Mad'ana Desirée Ribeiro de. 0 processo de implantação e implementação do Proeja no IFG - campus Goiânia: contradições, limites e perspectivas. 245 f. 2011. Tese (Doutorado em Educação). Universidade Federal de Goiás. Goiânia-GO, 2011. Disponível em:

$<$ http://ppge.fe.ufg.br/uploads/6/original_Tese.madna.final_PDF.pdf?1335454132 >. Aceso em: 20 jun. 2012.

COLONTONIO, Eloise Medice. O currículo integrado do Proeja: Trabalho, Cultura, Ciência e Tecnologia em tempos de semiformação. 118 f. 2010.

Dissertação (Mestrado em Educação). Universidade Federal do Paraná. Curitiba PR, 2010. Disponível em: <http://www.ppge.ufpr.br/teses/M10_colontonio.pdf>. Acesso em: 19 nov. 2011.

CORSO, Ângela Maria. As representações do trabalho junto a professores que atuam no Proeja: da representação moral do trabalho ao trabalho como autorrealização. 128 f. 2009. Dissertação (Mestrado em Educação). Universidade Federal do Paraná. Curitiba - PR, 2009. Disponível em:

<http://www.ppge.ufpr.br/teses/M09_corso.pdf>. Acesso em: 19 nov. 2011.

COSTA, Maria Adélia. Formas estruturantes da organização curricular e a materialização do Proeja no curso técnico de mecânica do CEFET-MG. $140 \mathrm{f}$. 2010. Dissertação (Mestrado em Educação). Centro Federal de Educação Tecnológica de minas Gerais - CEFET-MG. Belo Horizonte, MG. 2009.

COSTA, Rita de Cássia Dias. O Proeja para além da retórica: um estudo de caso sobre a trajetória da implantação do programa no Campus Charqueadas. 


\section{Trabalhonecessário}

Issn: 1808 - 799X

ano 10, no $15-2012$

108 f. 2009. Dissertação (Mestrado em Educação). Universidade Federal do Rio Grande do Sul. Porto Alegre, 2009. Disponível em:

$<$ http://www.lume.ufrgs.br/bitstream/handle/10183/18386/000729557.pdf?sequenc $\mathrm{e}=1$ >. Acesso em: 17 nov. 2011.

COSTA, Rosenilda Trindade. Jovens negras em processo de escolarização na EJA. 124 f. 2009. Dissertação (Mestrado em Educação). Pontifícia Universidade Católica de Goiás. Goiânia, 2009. Disponível em:

$<$ http://tede.biblioteca.ucg.br/tde_busca/arquivo.php?codArquivo=720>. Acesso em: 22 fev. 2012.

CRIZEL, Lilian Escandiel. O currículo de química do Proeja do IFRS-campus

Bento Gonçalves: o dito e o feito. 172 f. 2011. Dissertação (Mestrado em

Educação). Universidade Federal do Rio Grande do Sul. Porto Alegre-RS, 2011.

Disponível em:

$<$ http://www.lume.ufrgs.br/bitstream/handle/10183/37934/000823316.pdf?sequenc $\mathrm{e}=1>$. Acesso em: 20 jun. 2012.

DEBIASIO, Flávia de Jesus Mendes. Acesso, permanência e evasão nos cursos do Proeja em instituições de ensino de Curitiba - PR. 127 f. 2010. Dissertação (Mestrado em Tecnologia). Universidade Tecnológica Federal do Paraná (UTFPR) Curitiba - PR, 2010. Disponível em:

$<$ http://www.ppgte.ct.utfpr.edu.br/sites/default/files/dissertacoes/2010/331.pdf>. Acesso em: 19 nov. 2011.

DUARTE, Bárbara Regina Gonçalves Vaz. Reestruturação produtiva, formação e identidade: o Projeto Escola de Fábrica e a constituição identitária de jovens trabalhadores. 154 f. 2008. Dissertação (Mestrado em Educação). Universidade Federal de Pelotas. Pelotas-RS, 2008. Disponível em:

$<w w . d o m i n i o p u b l i c o . g o v . b r / d o w n l o a d / t e x t o / c p 058940 . p d f>$. Acesso em: 20 nov. 2011.

FONSECA, Ângela Carmem Abreu Fraga. A relação dos sujeitos educandos e educandas do PEPEJA com a apropriação dos conhecimentos de Física. 215 f. 2011. Dissertação (Mestrado em Educação). Centro Federal de Educação Tecnológica de minas Gerais - CEFET-MG. Belo Horizonte, MG. 2011.

FREITAS, Rony Cláudio de Oliveira. Produções colaborativas de professores de matemática para um currículo integrado do Proeja-IFES. 306 f. 2010. Tese (Doutorado em Educação). Universidade Federal do Espírito Santo. Vitória, 2010. 


\section{Trabalhonecessário}

Issn: 1808 - 799X

ano 10, no $15-2012$

Disponível em: <http://www.ppge.ufes.br/teses/2010/Rony\%20Freitas.pdf>. Acesso em: 18 nov. 2011.

GARCIA, Lénin Tomazett. A política de educação de jovens e adultos e educação profissional em Goiás: tranças desencadeadas com o proeja. $119 \mathrm{f}$. 2011. Dissertação (Mestrado em Educação). Universidade Federal de Goiás. Goiânia, 2011. Disponível em: $<$ http://forumeja.org.br/go/sites/forumeja.org.br.go/files/dissertacaolenintomazett.p df $>$. Acesso em: 17 nov. 2011.

GOMES, Ângela. Envelhecer saudável no mundo do trabalho: uma análise da intenção dos educandos no módulo "saúde e cidadania" do Programa Integrar. 249 f. 2007. Dissertação (Mestrado em Educação). Universidade Federal do Rio Grande do Sul. Porto Alegre, 2007. Disponível em:

$<$ http://www.lume.ufrgs.br/bitstream/handle/10183/12187/000623374.pdf?sequenc $\mathrm{e}=1>$. Acesso em: 20 nov. 2011.

GOTARDO, Renata Cristina da Costa. A formação profissional no ensino médio integrado: discussões acerca do conhecimento. 110 f. 2009 . Dissertação (Mestrado em Educação). Universidade Estadual do Oeste do Paraná. Cascavel PR, 2019. Disponível em: < http://cac-

php.unioeste.br/pos/media/File/educacao/Renata\%20Gotardopdf.pdf >. Acesso em: 10 nov. 2011.

GRAMSCI, Antônio. Cadernos do cárcere. vol. 2. 6. ed. Tradução: Carlos Nelson Coutinho. Civilização Brasileira, 2011.

HOTZ, Karina Griggio. Avaliação da implementação do Proeja em municípios do Oeste do Paraná (2008-2009). 263 f. 2010. Dissertação (Mestrado em Educação). Universidade Estadual do Oeste do Paraná. Cascavel-PR, 2010. Disponível em: <http://www.dominiopublico.gov.br/download/texto/cp134125.pdf>. Acesso em: 17 nov. 2011.

IVO, Andressa Aita. Ensino Profissional e Educação Básica: estudo de caso da implantação de um curso técnico na modalidade de jovens e adultos (Proeja). 114 f. 2010. Dissertação (Mestrado em Educação). Universidade Federal de Pelotas.

Pelotas, 2010. Disponível em: <http://www.ufpel.edu.br/tede/tde_arquivos/18/TDE2010-09-01T193240Z-546/Publico/Andressa_Aita_Ivo_Dissertacao.pdf >. Acesso em: 18 nov. 2011. 


\section{Trabalhonecessário}

Issn: 1808 - 799X

ano 10, no $15-2012$

JACINTO, Everton L. A atividade pedagógica do professor de Matemática do Proeja. 223 f. 2011. Dissertação (Mestrado em Ensino de Ciências e Matemática). Universidade Federal de Goiás. Goiânia-GO, 2011. Disponível em: $<$ http://bdtd.ufg.br/tedesimplificado/tde_busca/arquivo.php?codArquivo=2190>. Acesso em: 20 jun. 2012.

KLINSKI, Cláudia dos Santos. Ingresso e permanência de alunos com Ensino Médio concluído no Proeja e IF Sul-Rio-grandense - Campus Charqueadas. 145 f. 2009. Dissertação (Mestrado em Educação). Universidade Federal do Rio Grande do Sul. Porto Alegre, 2009. Disponível em:

$<$ http://www.lume.ufrgs.br/bitstream/handle/10183/21853/000738791.pdf?sequenc $\mathrm{e}=1>$. Acesso em: 18 nov. 2011.

LAMPERT, Fernanda G. Proeja: mais do que uma possibilidade de qualificação profissional? 118 f. 2011. Dissertação (Mestrado em Educação). Universidade do Vale do Rio dos Sinos - Unisinos. São Leopoldo-RS, 2011. Disponível em: $<$ http://bdtd.unisinos.br/tde_arquivos/10/TDE-2011-12-07T154856Z1648/Publico/FernandaGabrielaLampert.pdf>. Acesso em: 08 maio 2012.

LIRA, Carla Andrezza A. Lopes. Formação continuada de professores para o PROEJA: a realidade do Instituto Federal de Educação, Ciência e Tecnologia do Pará - IFPA. Dissertação (Mestrado em Educação). Universidade Federal do Ceará. Fortaleza-CE, 2011Disponível em:

$<$ http://www.teses.ufc.br/tde_busca/arquivo.php?codArquivo=7036>. Acesso em: 20 jun. 2012.

LOPES, Alice C. Políticas curriculares: continuidade ou mudança de rumos? Revista Brasileira de Educação. [online]. 2004, n. 26, p. 109-118. Disponível em: <http://www.scielo.br/pdf/rbedu/n26/n26a08.pdf>. Acesso em: 21 mar. 2012.

LOPES, Josué. Educação profissional integrada com a Educação Básica: 0 caso do currículo integrado do Proeja. 190 f. 2009. Dissertação (Mestrado em Educação). Centro Federal de Educação Tecnológica de minas Gerais - CEFETMG. Belo Horizonte, MG. 2009.

MARCOLLA, Valdinei. As tecnologias da informação e comunicação na prática pedagógica de professores do curso técnico integrado do Proeja. 169 f. 2011. Tese (Doutorado em Educação). Universidade Federal de Pelotas. Pelotas-RS, 2011. Disponível em: 


\section{Trabalhonecessário}

Issn: 1808 - 799X

ano 10, no $15-2012$

$<$ http://taniaporto.dominiotemporario.com/doc/TT_2011_valdinei.pdf>. Acesso em: 20 jun. 2012.

NASCIMENTO, Martha de Cássia. Práticas administrativas e pedagógicas desenvolvidas na implementação do Proeja na EAFAJT: discurso e realidade. 257 f. 2009. Dissertação (Mestrado em Educação). Universidade de Brasília. Brasília, 2009. Disponível em:

<http://repositorio.bce.unb.br/bitstream/10482/4690/1/2009_MarthadeCassiaNasci mento.pdf>. Acesso em: 17 nov. 2011.

NORO, Margarete Maria Chiapinotto. Gestão de processos pedagógicos no Proeja: razão de acesso e permanência. 177 f. 2011. Dissertação (Mestrado em Educação). Universidade Federal do Rio Grande do Sul. Porto Alegre, 2011. Disponível em:

<http://www.lume.ufrgs.br/bitstream/handle/10183/36311/000817419.pdf?sequenc $\mathrm{e}=1>$. Acesso em: 19 mar. 2012.

NOSELLA, Paolo. A escola de Gramsci. 4. ed. São Paulo: Cortez, 2010. 208 p.

NUNES, Patrícia dos Santos. Em busca do tesouro: inserção profissional e inclusão digital nas trajetórias de egressos/integralizados de um curso Técnico de Informática - Proeja. 179 f. 2011. Tese (Doutorado em Educação). Universidade do Vale do Rio dos Sinos. São Leopoldo-RS, 2011. Disponível em: $<$ http://bdtd.unisinos.br/tde_arquivos/10/TDE-2012-02-16T162016Z1693/Publico/PatriciadosSantosNunes.pdf >. Acesso em: 20 jun. 2012.

OLIVEIRA, Dalila Andrade. Das políticas de governo às políticas de Estado: reflexões sobre a atual agenda educacional brasileira. Educação e Sociedade. Campinas - SP. v. 32, n. 115, p. 323-337, abr./jun. 2011. Disponível em: <http://www.scielo.br/pdf/es/v32n115/v32n115a05.pdf>. Acesso em: 06 fev. 2012.

OLIVEIRA, Maria Clarice Rodrigues de. Cruzando as fronteiras: do trabalho na fumicultura, da formação profissional e dos saberes locais. 189 f. 2011.

Dissertação (Mestrado em Educação). Universidade Federal do Rio Grande do Sul. Porto Alegre, 2011. Disponível em:

<http://www.lume.ufrgs.br/bitstream/handle/10183/36316/000817453.pdf?sequenc $\mathrm{e}=1>$. Acesso em: 19 mar. 2012.

PACHECO, Hasla de Paula. A experiência do Proeja em Contagem: interseção entre EJA e Educação Profissional. 154 f. 2010. Dissertação (Mestrado em Educação). Universidade Federal de Minas Gerais. Belo Horizonte-MG, 2010. 


\section{Trabalhonecessário}

Issn: 1808 - 799X

ano 10, no $15-2012$

Disponível em:

<http://www.bibliotecadigital.ufmg.br/dspace/bitstream/1843/BUDB-

8CSLNN/1/dissertacaohaslapacheco.pdf> Acesso em: 18 out. 2011.

PEIXOTO, Edson Maciel. Políticas de Educação Profissional e Tecnológica: a influência dos princípios de gestão democrática nas deliberações do CEFET-MG. 205 f. 2009. Dissertação (Mestrado em Educação) Universidade de Brasília. Brasília, 2009. Disponível em:

$<$ http://repositorio.bce.unb.br/bitstream/10482/4234/1/2009_EdsonMacielPeixoto.p df>. Acesso em: 18 nov. 2011.

PEREIRA, Josué Vidal. O Proeja no Instituto Federal de Goiás - campus de Goiânia. 154 f. 2011. Dissertação (Mestrado em Educação). Universidade de Brasília. Brasília-DF, 2011. Disponível em: <http://biblioteca.fe.unb.br/pdfs/201104-291546Josue.pdf>. Acesso em: 19 nov. 2011.

REPOLÊS, Maria Catarina Paiva. Reflexões sobre avaliação e seleção de materiais didáticos convencionais e integrativos das TDIC para o ensino de Língua Inglesa no Proeja. 103 f. 2011. Dissertação (Mestrado em Estudos de Linguagens). Centro Federal de Educação Tecnológica. Belo Horizonte-MG, 2011.

ROCHA, Wellington M. Educação de jovens e adultos e a evasão escolar: 0 caso do Instituto Federal do Ceará - campus de Fortaleza. 154 f. 2011.

Dissertação (Mestrado em Educação). Universidade Federal do Ceará. FortalezaCE, 2011. Disponível em:

$<$ http://www.teses.ufc.br/tde_busca/arquivo.php?codArquivo=6706>. Acesso em: 20 jun. 2012.

RODRIGUES, Dorisdei Valente. O Projeto Proeja/Transiarte: uma experiência de pesquisa-ação em ciberarte. 127 f. 2010. Dissertação (Mestrado em Educação). Universidade de Brasília. Brasília-DF, 2010. Disponível em: $<$ http://bdtd.bce.unb.br/tedesimplificado/tde_busca/arquivo.php?codArquivo=6210 >. Acesso em: 19 nov. 2011.

RODRIGUES, Manoel Antônio Quaresma. O Proeja no Cefet-PA: o currículo prescrito, concebido e percebido na perspectiva da integração. 117 f. 2009. Dissertação (Mestrado em Educação). Universidade de Brasília. Brasília-DF, 2009. Disponível em: 


\section{Trabalhonecessário}

Issn: 1808 - 799X

ano 10, no $15-2012$

<http://repositorio.bce.unb.br/bitstream/10482/4285/1/2009_ManoelAntonioQuares maRodrigues.pdf>. Acesso em: 17 nov. 2010.

ROMANOWSKI, Joana Paulin; ENS, Romilda Teodora. As pesquisas denominadas do tipo "estado da arte" em educação. Revista Diálogo

Educacional, Curitiba: PUC-PR, vol. 6, n. 19, set./dez., p. 37-50, 2006. Disponível em: <http://redalyc.uaemex.mx/redalyc/pdf/1891/189116275004.pdf >. Acesso em: 25 fev. 2012.

SACRISTÁN, J. Gimeno. O currículo: uma reflexão sobre a prática. Tradução Ernani F. da F. Rosa. 3. ed. Porto Alegre: Artmed, 2000.

SANTOS, Claitonei de Siqueira. Jovens do Proeja de Urutaí: mediações entre a escola e o mundo do trabalho. 179 f. 2011. Dissertação (Mestrado em Educação). Pontifícia Universidade Católica de Goiás, Goiânia, 2011. Disponível em: <http://forumeja.org.br/go/sites/forumeja.org.br.go/files/Disserta\%C3\%A7\%C3\%A3 ०\%20Claitonei\%20de\%20Siqueira\%20Santos.pdf>. Acesso em: 22 fev. 2012.

SANTOS, Júlio de Souza. Os sentidos da formação profissional para os lavradores do entorno do IFES-campus Itapina Vitória. 145 f. 2010.

Dissertação (Mestrado em Educação). Universidade Federal do Espírito Santo. Vitória, 2010. Disponível em:

<http://www.ppge.ufes.br/dissertacoes/2010/J\%DALIO\%20SANTOS.pdf>. Acesso em: 20 fev. 2012.

SANTOS, Renato Lopes. Proeja e diversidade étnico-racial: desafio e ensejo para formação de professores. 2011. 162 f. Dissertação (Mestrado em Educação). Centro Federal de Educação Tecnológica de minas Gerais - CEFET-MG. Belo Horizonte, MG. 2011.

SAVIANI, Dermeval. Educação brasileira: estrutura e sistema. 8. ed. CampinasSP: Autores Associados, 2000.

SILVA, Carla Odete Balestro. Ad-mirando o professor de formação técnica: o fazer-se docente no encontro com o Proeja em dois campi do IFSUL. 2011. $174 \mathrm{f}$. Dissertação (Mestrado em Educação). Universidade Federal do Rio Grande do Sul. Porto Alegre, 2011. Disponível em:

$<$ http://www.lume.ufrgs.br/bitstream/handle/10183/33669/000789344.pdf?sequenc $\mathrm{e}=1>$. Acesso em: 20 nov. 2011. 


\section{Trabalhonecessário}

Issn: 1808 - 799X

ano 10, no $15-2012$

SILVA, Mônica Ribeiro. A política de integração curricular no âmbito do PROEJA: entre discursos, sujeitos e práticas. Ensaio: avaliação e políticas públicas em Educação. 2011, vol. 19, n. 71, p. 307-326.

SILVA, Jussara das Graças T. A construção do currículo integrado no âmbito do Proeja/PR: a questão da indissociabilidade entre formação geral e formação específica. 206 f. 2010. Dissertação (Mestrado em Educação). Universidade Federal do Paraná. Curitiba-PR, 2010. Disponível em:

<http://dspace.c3sl.ufpr.br/dspace/bitstream/handle/1884/24985/Silva,\%20Jussara $\% 20$ das\%20Gracas\%20Trindade\%20e.pdf?sequence=1 >. Acesso em: 19 mar. 2012.

SILVA, Maria L. Currículo integrado e formação continuada de professores: entre desafios e sonhos no Proeja - IFPA. 161 f. 2011. Dissertação (Mestrado em Educação). Universidade Federal do Ceará. Fortaleza-CE, 2011. Disponível em: $<$ http://www.teses.ufc.br/tde_busca/arquivo.php?codArquivo=6382>. Acesso em: 20 jun. 2012.

SIQUEIRA, André Boccasius. Alunos do Proeja: histórias de estudantes do Instituto Federal de Educação, ciência e Tecnologia Sul-Riograndense, Campus de Sapucaia do Sul. 301 f. 2010. Tese (Doutorado em Educação). Universidade Federal do Vale do Rio dos Sinos. São Leopoldo, 2010. Disponível em: <http://bdtd.unisinos.br/tde_arquivos/10/TDE-2010-07-13T095327Z1162/Publico/AndreSiqueiraEducacao.pdf>. Acesso em: 18 nov. 2011.

THOMPSON, Edward Palmer. Os românticos: a Inglaterra na era revolucionária. Rio de Janeiro: Civilização Brasileira, 2002.

YAMANOE, Mayara Cristina P. Programa Nacional de Integração da Educação Profissional com a Educação Básica na Modalidade de Educação de Jovens e Adultos (Proeja): reflexões acerca do trabalho como princípio educativo. $83 \mathrm{f}$. 2011. Dissertação (Mestrado em Educação). Universidade Estadual do Oeste do Paraná. Cascavel - PR, 2011. Disponível em: <http://cacphp.unioeste.br/pos/media/File/educacao/Dissertacao_Mayara_Yamanoe.pdf>. Acesso em: 10 nov. 2011.

ZANETTI NETO, Giovani. Socialização e educação profissional: um estudo do Proeja-CEFETES. 100f. 2009. Dissertação (Mestrado em Educação). Universidade Federal do Espírito Santo. Vitória, 2009. Disponível em: 


\section{Trabalhonecessário}

Issn: 1808 - 799X

ano 10, no $15-2012$

<http://www.ppge.ufes.br/dissertacoes/2009/GIOVANI\%20ZANETTI.pdf >. Acesso em: 18 nov. 2011.

ZIM, Aline Stefânia. Arte, educação e narrativa no Proeja-Transiarte: ensaios e fragmentos. 105 f. 2010. Dissertação (Mestrado em Educação). Universidade de Brasília. Brasília-DF, 2010. Disponível em:

<http://bdtd.bce.unb.br/tedesimplificado/tde_busca/arquivo.php?codArquivo=6537 >. Acesso em: 19 nov. 2011. 